\title{
Angiotensin II Regulates Dendritic Cells through Activation of NF-kB /p65, ERK1/2 and STAT1 Pathways
}

\author{
Yan Meng ${ }^{a}$ Chen Chen ${ }^{b}$ Yang Liuc Cui Tiana Hui-Hua Lic, \\ aDepartment of Pathology and Pathophysiology, School of Basic Medical Sciences, Capital Medical \\ University, Beijing, 'beijing LuHe Hospital, Affiliated Hospital of Capital Medical University, Beijing \\ 'Department of Cardiology, Institute of Cardiovascular Diseases, First Affiliated Hospital of Dalian \\ Medical University, Dalian, dDepartment of Nutrition and Food Hygiene, School of Public Health, Dalian \\ Medical University, Dalian, China
}

\section{Key Words}

Angiotension II • Dendritic cells • Activation $・$ Inflammation • Signaling pathways

\begin{abstract}
Background: Activation of dendritic cells (DCs) is necessary to initiate immune responses. Angiotensin II (Ang II) has been reported to have a proinflammatory and immunomodulatory function. However, the role of Ang II in regulation of DCs and the underlying mechanisms remain illdefined. Methods: The effects of Ang II on the proliferation, maturation, phagocytosis, migration, and communication with T cells of DCs were analysed utilizing MTT, flow cytometry, ELISA, transwell assay and mixed lymphocyte culture. Results: We found that Ang II treatment significantly inhibited proliferation and phagocytic activity of DCs, but promoted the DC maturation and migration well as the expression of pro-inflammatory cytokines by DCs. In addition, Ang II also stimulated DC-mediated T cell proliferation. These effects were associated with activation of p65/NF-kB, ERK1/2 and STAT1 signaling pathways in DCs. Conclusions: Our results demonstrate that Ang II activates DCs partially through p65/NF-kB, ERK1/2 and STAT1 pathways, and suggest a potential therapeutic target of DC-mediated inflammatory disorders.
\end{abstract}

\section{Introduction}

Dendritic cells (DCs) are specialized antigen-presenting cells and play an important role in immune responses [1]. These cells provide a link between the innate and adaptive immune system. The precursors originating from the bone marrow and the thymus can differentiate into DCs. DCs enter the circulation and reside to the peripheral tissue. After being connected with immune stimulants, DCs take up and process antigens in peripheral tissues and then migrate to secondary lymphoid organs, where they activate naive T cells. The maturation

Hui-Hua Li

KARGER
Department of Cardiology, Institute of Cardiovascular Diseases, First Affiliated Hospital of Dalian Medical University, Dalian (China)

E-Mail hhli1995@yahoo.com 
process of DCs is a multi-step process, including a decrease of the endocytic ability, high cell surface expression of con-stimulatory (CD40, CD80 and CD86) and major histocompatibility complex (MHC) class II molecules, and cytokine induction, especially TNF- $\alpha$, IL-12 and IL-10 [2, 3]. The common DCs maturation inducers include lipopolysaccharides (LPS), CpGoligonucleotide (CpG ODN), tumor necrosis factor (TNF $\alpha$ ), type I interferon (IFN- $\gamma$ ), immune complex and endogenous ligand [4]. Recent studies showed that Ang II was also able to induce DCs activation [5].

LPS, a cell wall component of gram-negative bacteria, can induce most of the clinical manifestations of bacterial infections, including inflammation, fever and septic shock [6]. LPS can also induce the production of proinflammatory cytokines, such as interleukin-1 (IL-1), IL-6, IL-12, IFN- $\gamma$ and TNF- $\alpha$. LPS binds Toll-like receptor 4(TLR4) to trigger several crucial intracellular signaling responses including activation of transcription factor nuclear factor- $\kappa \mathrm{B}(\mathrm{NF}-\kappa \mathrm{B})$ and induction of proinflammatory cytokines.

Angiotensin II (Ang II) is a major bioactive hormone peptide of rennin-angiotensin system, which plays a central role in cardiovascular homeostasis [7, 8]. It was reported that Ang II is present and functional in multiple immune cells such as macrophages, T cells and nature killer (NK) cells. Moreover, accumulating evidence suggest that the pro-inflammatory actions of Ang II is at least partially via activation of DCs [9]. Thus Ang II performs as a potent modulator in the immune system.

A better understanding of DCs activations is important for exploring their roles in inflammatory responses and the related inflammatory diseases. We investigated the effect of Ang II or LPS on the immune-modulating properties of DCs, including proliferation, maturation, migration, phagocytosis, and communication with T cells. Our results indicated that Ang II and LPS can induce similar responses on DCs, demonstrating the importance of Ang II in the DC-mediated immune response.

\section{Materials and Methods}

\section{Antibodies and reagents}

RPMI-1640, fetal bovine serum (FBS) and phosphate-buffered saline (PBS) were purchased from Hyclone (South Logan, UT). Ang II and LPS from Salmonella abortus equi were purchased from SigmaAldrich (St Louis, MO). The antibodies were products of Cell Signaling Technology (Beverly, MA). The ELISA assay kits for IL- 6 and IFN- $\gamma$ analysis were products of Dakewe Biotech Company. Carboxyfluorescein diacetate-succinimidyl ester (CFSE) was from Dojindo Laboratories. All other chemicals were from SigmaAldrich (St Louis, MO), unless specified otherwise.

\section{Cell culture and treatment}

DC2.4 cells, a murine bone marrow-derived DC line, were provided by Military Institute of Basic Medical Science, and cultured in RPMI-1640 supplemented with $10 \%$ fetal calf serum, penicillin (100 U/ml) and streptomycin $(100 \mathrm{mg} / \mathrm{ml})$ at $37^{\circ} \mathrm{C}$ under a humidified atmosphere of $95 \%$ air and $5 \% \mathrm{CO}_{2}$. To evaluate the difference between Ang II and LPS, DC2.4 were treated with LPS (200 ng/ml) and Ang II (100 ng/ml) respectively, for the indicated time points after starvation over night.

\section{MTT assay}

To determine the metabolic activity of cells, MTT assays were performed. Cells were seeded in 96well plates at a density of $1 \times 10^{3}$ cells per well. Wells containing culture medium only served as blank controls for non-specific dye reduction. For the measurement MTT solution was added to each well to a final concentration of $0.5 \mathrm{mg} / \mathrm{ml}$. After $4 \mathrm{~h}$ of incubation at $37^{\circ} \mathrm{C}$, the medium was removed and the formazan crystals were dissolved in DMSO. Absorbance was measured at $490 \mathrm{~nm}$ using a microplate reader.

Flow cytometry

The surface expression of antigen markers was performed by flow cytometry. DCs were collected and resuspended in PBS at a concentration of $2 \times 10^{5} / \mathrm{ml}$. Cells were incubated with the following anti-mouse 
monoclonal antibodies (eBioscience): FITC-conjugated anti-CD40, anti-CD80 and anti-MHCII for $30 \mathrm{~min}$ at room temperature in the dark. Appropriate isotype-matched immunoglobulins were used as negative control. Then cells were analyzed on a FACSCalibur flow cytometer with CellQuest software (Becton Dickinson, San Jose, CA, USA). Results were expressed as the percentages of positive cells calculated as specific antibody minus the value obtained from the isotype control.

\section{Cell migration assay}

Cell migration was determined in Boyden chambers as described. Briefly, cells were serum-starved for $8 \mathrm{~h}$ and then exposed to LPS, Ang II and negative control for $12 \mathrm{~h}$. Then $4 \times 10^{4}$ cells were seeded to the upper chamber. Cell migration was allowed to proceed for $16 \mathrm{~h}$ at $37^{\circ} \mathrm{C}$ in $5 \% \mathrm{CO}_{2}$. Cells migrated to the lower surface of the filter were stained $1 \%$ crystal violet in $2 \%$ ethanol for $20 \mathrm{~min}$, and quantified by cell counting under high magnification.

\section{Phagocytosis}

Phagocytosis was measured by the cellular uptake of fluorescein isothiocyanate (FITC)-dextran and quantified by flow cytometry. Approximately $5 \times 10^{5}$ cells per sample were incubated in medium containing FITC-dextran (1 mg/mL, molecular weight 40 000, Sigma, St Louis, MO) for 60 minutes. After incubation, cells were washed twice with cold PBS to stop phagocytosis. After removed excess dextran, cells were fixed in cold $1 \%$ formalin. The quantitative uptake of FITC-dextran by cells was determined by fluorescenceactivated cell sorting (FACS), and the results were expressed in mean fluorescence intensity (MFI) values. At least 10000 cells per sample were analyzed.

Cytokine assay by ELISA

Cytokine concentrations of IL- 6 and IFN- $\gamma$ in supernatants from DCs culture were measured with commercially available Enzyme-Linked Immuno-Sorbent Kits from Dakewe Biotech Company according to the manufacturer's instructions.

Co-culture of lymphocytes and DCs

Single-cell suspensions from spleen of BALB/c mice were obtained by grinding and filtration through nylon mesh. The lymphocytes were enriched with Ficoll (TBDscience). Lymphocytes $\left(1 \times 10^{6} / \mathrm{mL}\right)$ were stained with CFSE and then co-cultured with C57BL/6 bone marrow-derived DCs $\left(1 \times 10^{5} / \mathrm{mL}\right)$ after Mitomycin C treatment (Roche). Five days later, harvested cells were stained with PE-conjugated anti-CD3 (eBioscience) and $\mathrm{T}$ cells proliferation was evaluated by flow cytometry.

\section{Western blot analysis}

Total protein was isolated from different treated DCs. Cells were collected, repeatedly frozen and thawed in NP-40 lysis buffer with $1 \%$ PMSF. The lysate was centrifuged at $12,000 \times$ g for $10 \mathrm{~min}$ at $4^{\circ} \mathrm{C}$, and the supernatant was collected. Thirty $\mu$ g protein per sample was loaded on a 10\% SDS-PAGE gel and transferred onto nitrocellulose membranes. After being blocked with 5\% nonfat milk for $30 \mathrm{~min}$, the membranes were incubated with primary antibodies as indicated overnight and then incubated with horseradish peroxidaseconjugated secondary antibody for $1 \mathrm{~h}$. The blots were developed with an enhanced chemiluminescence detection system (Beijing Sage creation) and the bands were scanned, and densitometry analysis was performed with the software Image $\mathrm{J} 2 \mathrm{x}$.

Statistical analysis

Students paired t-test was used to determine the significance of differences between means, and $\mathrm{P}<$ 0.05 was taken as indicating statistical significance.

\section{Results}

Ang II inhibits the proliferation of DCs

To evaluate the proliferation of DCs in response to Ang II and LPS stimulation, we treated DCs with Ang II (100 ng/ml) or LPS (200 ng/ml) after overnight starvation. MTT 
analysis revealed that LPS significantly inhibited the proliferation of DCs during 12-24 h, whereas Ang II only markedly inhibited this effect after $24 \mathrm{~h}$. Notably, the proliferation of DCs was significantly higher in Ang II treatment than in LPS treatment at $24 \mathrm{~h}$. These results indicate that Ang II has a lower inhibitory ability on DC proliferation than LPS (Fig. 1).

\section{Ang II stimulates the phenotypic maturation of DCs}

To investigate the effect of LPS and Ang II on DCs maturation, DCs were treated with Ang II $(100 \mathrm{ng} / \mathrm{ml})$ or LPS (200 ng/ml) for 12-48 h. The maturation surface molecules of DCs, including MHCII, CD40 and CD80, were detected by flow cytometry. As shown in Fig. 2, both Ang II and LPS significantly increased the phenotypic maturation of DCs at different time points. After Ang II stimulation, the levels of MHCII and CD40 were peaked at $12 \mathrm{~h}$, whereas CD80 was peaked at $24 \mathrm{~h}$. While LPS treatment led to a marked increase in the levels of MHCII, CD40 and CD80 at $12 \mathrm{~h}$ compared to $0 \mathrm{~h}$, peaked at $24 \mathrm{~h}$, and then decreased almost to the baseline at $48 \mathrm{~h}$. Interestingly, the levels of MHCII and CD40 were significantly lower in Ang II treatment than that in LPS treatment at 12 and $24 \mathrm{~h}$.

\section{Ang II promotes the migration of DCs}

To determine the effect of Ang II and LPS on the migration of DCs, We treated DCs with Ang II (100 ng/ml) or LPS (200 ng/ml) for $48 \mathrm{~h}$, and transwell assay was performed. Both Ang II and LPS significantly promoted the migration of DCs (about 1.7-fold and 2.0-fold, respectively) as compared with control, and there was no marked difference between Ang II and LPS treatment (Fig. 3).These results suggest Ang II displays a similar effect with LPS on migratory activity.

\section{Ang II inhibits the phagocytosis of DCs}

Maturation of DCs is associated with decreased endocytic ability. To further examine the Ang II and LPS on the phagocytosis of DCs, we treated DCs with Ang II (100 ng/ml) or LPS (200 ng/ml) for $48 \mathrm{~h}$. The phagocytosis was measured by flow cytometry. As shown in Fig. 4, Ang II and LPS significantly decreased the endocytic ability of DCs by $50 \%$ and

Fig. 1. Ang II inhibits the proliferation of DCs. DCs were treated with Ang II $(100 \mathrm{ng} / \mathrm{ml})$ or LPS (200 $\mathrm{ng} / \mathrm{ml}$ ) after overnight starvation. MTT analysis of cell proliferation was performed. Data were expressed as mean \pm SEM from three independent experiments. ${ }^{*} P<0.05$ versus control. ${ }^{\#} P<0.05$ versus $L P S$.
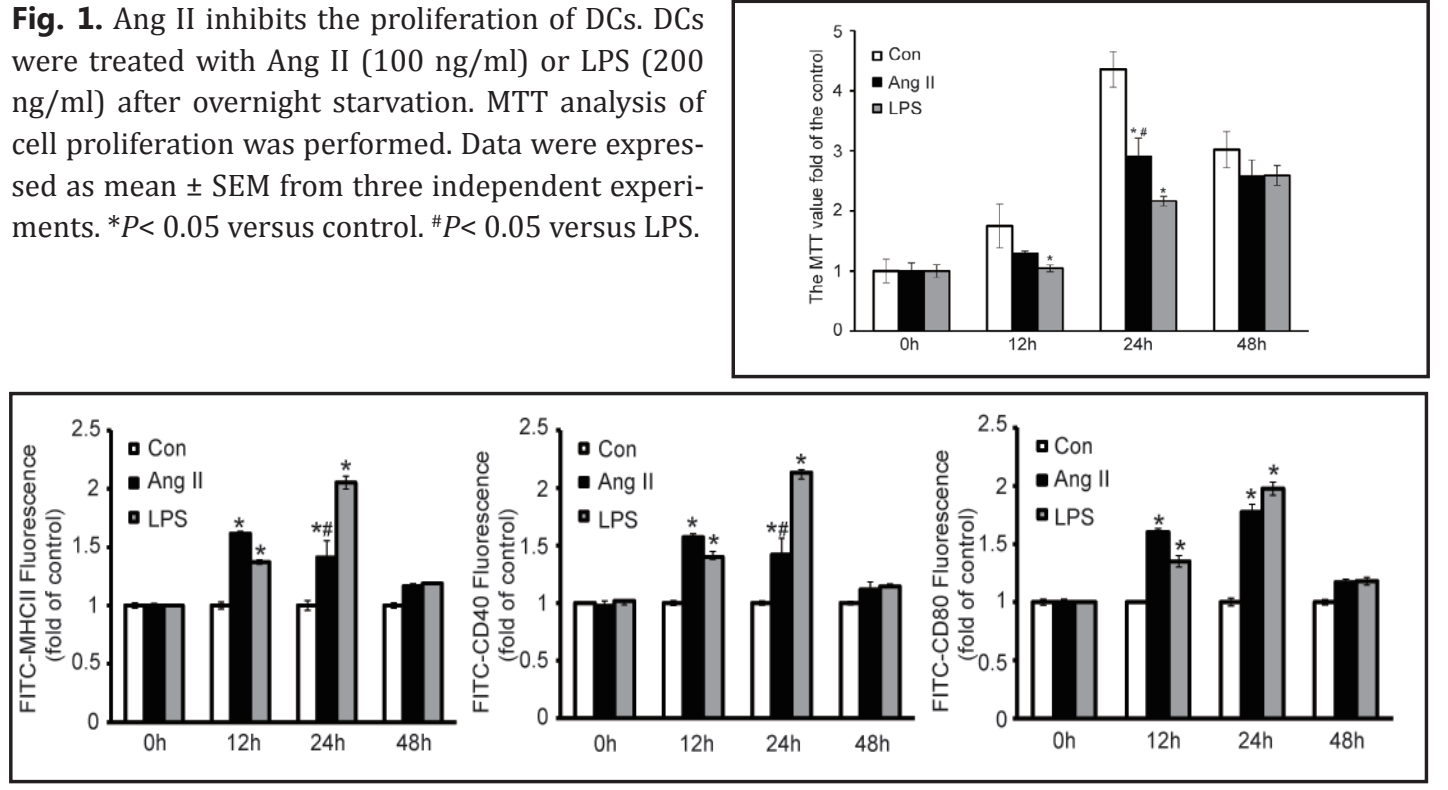

Fig. 2. Ang II increase the phenotypic maturation of DCs. DCs were treated with Ang II (100 ng/ml) or LPS (200 ng/ml) for $48 \mathrm{~h}$. The expression of surface markers on DCs was analyzed with flow cytometry. The numbers indicates the percentages of positive cells. Histograms showed the expression of MHCII, CD40 and CD80. Data were expressed as mean \pm SEM from three independent experiments. ${ }^{*} P<0.05$ versus control. ${ }^{\#} P<0.05$ versus LPS. 
Fig. 3. Ang II promotes the migration of DCs. DCs were treated with Ang II (100 ng/ml) or LPS (200 $\mathrm{ng} / \mathrm{ml}$ ) for $48 \mathrm{~h}$. Cell migration was measured by stained with $1 \%$ crystal violet in $2 \%$ ethanol. A representative field was shown for each condition (top). Quantitative analysis of cell migration was shown (bottom). Bar: $20 \mu \mathrm{m}$. Data were expressed as mean \pm SEM from three independent experiments. ${ }^{*} P<0.05$ versus control.
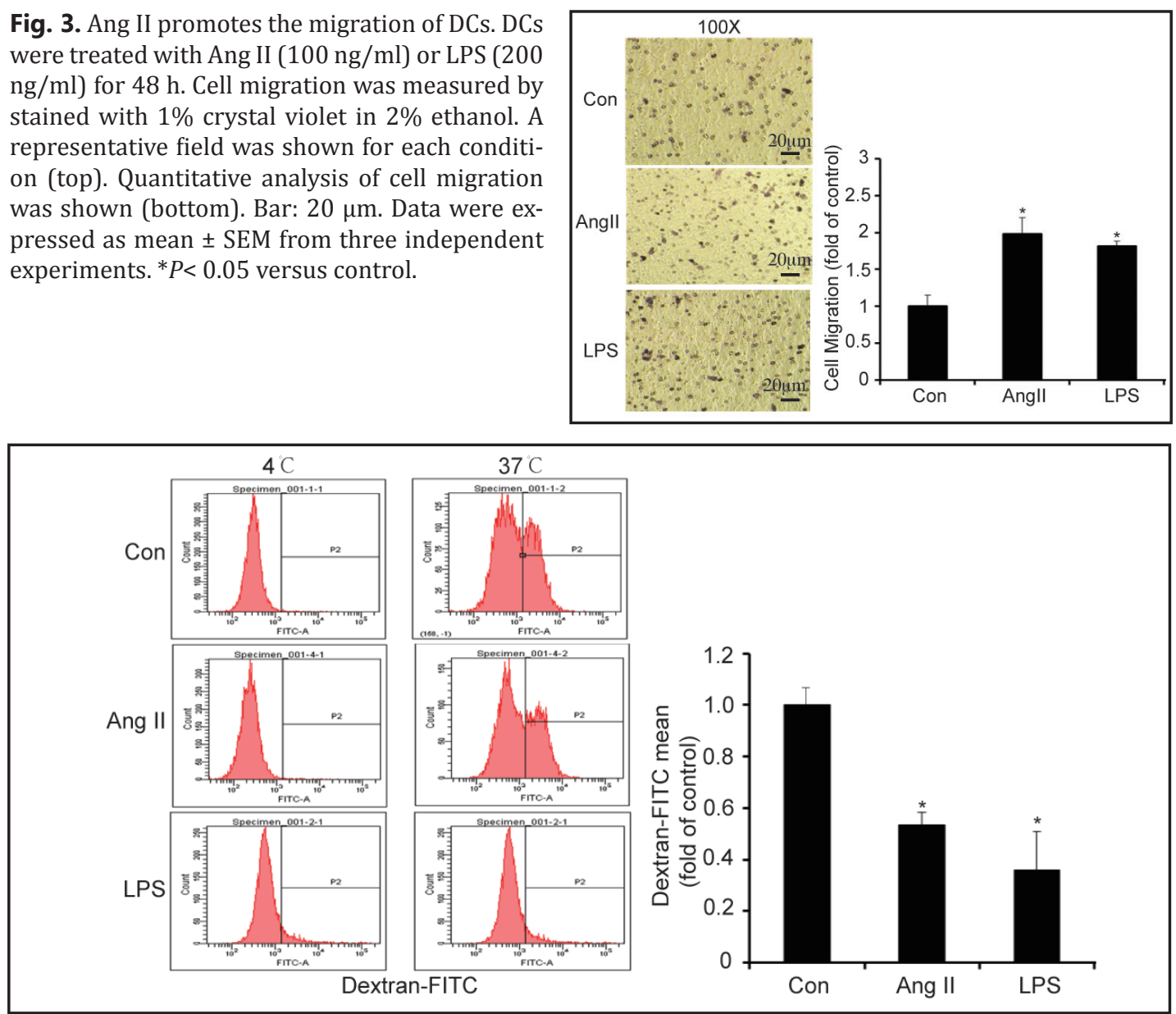

Fig. 4. Ang II inhibits the phagocytosis of DCs. DCs were treated with Ang II (100 ng/ml) or LPS (200 ng/ml) for $48 \mathrm{~h}$. Phagocytosis label by FITC-Dextran were detected by flow cytometry. A representative experiment was shown for each condition. Data were expressed as mean \pm SEM from three independent experiments. $* P<0.05$ versus control.

65\%, respectively, and there was no marked difference between Ang II and LPS treatment, indicating that Ang II and LPS have a similar inhibitory effect on phagocytosis of DCs.

Ang II induces the cytokine secretion of DCs

To test the effect of Ang II and LPS on the production of proinflammatory cytokines including IL- 6 and IFN- $\gamma$, DCs were treated with Ang II $(100 \mathrm{ng} / \mathrm{ml})$ or LPS (200 ng/ml) for $48 \mathrm{~h}$, and protein concentration was determined by ELISA. As shown in Fig. 5, both Ang II and LPS stimulation resulted in a significant increase of both IL-6 and IFN- $\gamma$ compared with control in DCs. The level of IFN- $\gamma$ was significantly higher in Ang II stimulation than that in LPS.

\section{Ang II promotes DC-mediated T cell proliferation}

To assess the effect of Ang II and LPS on DC-mediated T cell proliferation, we cocultured DCs and T lymphocyte and then treated with Ang II and LPS. Flow cytometry was performed with PE-conjugated anti-CD3. As shown in Fig. 6, both LPS- and Ang II-treated DCs significantly increased the proliferation of T cells by about 7- and 4-fold, respectively. The DC-mediated proliferation of T cells was also markedly lower in Ang II treatment and that in LPS stimulation. 
Fig. 5. Ang II stimulates the cytokine secretion of DCs. DCs were treated with Ang II (100 ng/ $\mathrm{ml}$ ) or LPS (200 ng/ml) for $48 \mathrm{~h}$. The cytokine concentrations of IL-6 and IFN- $\gamma$ in supernatants from DC culture medium were analyzed with ELISA. Data were presented as mean \pm SEM from three independent experiments. ${ }^{*} P<0.05$ versus control. ${ }^{\#} P<0.05$ versus LPS.
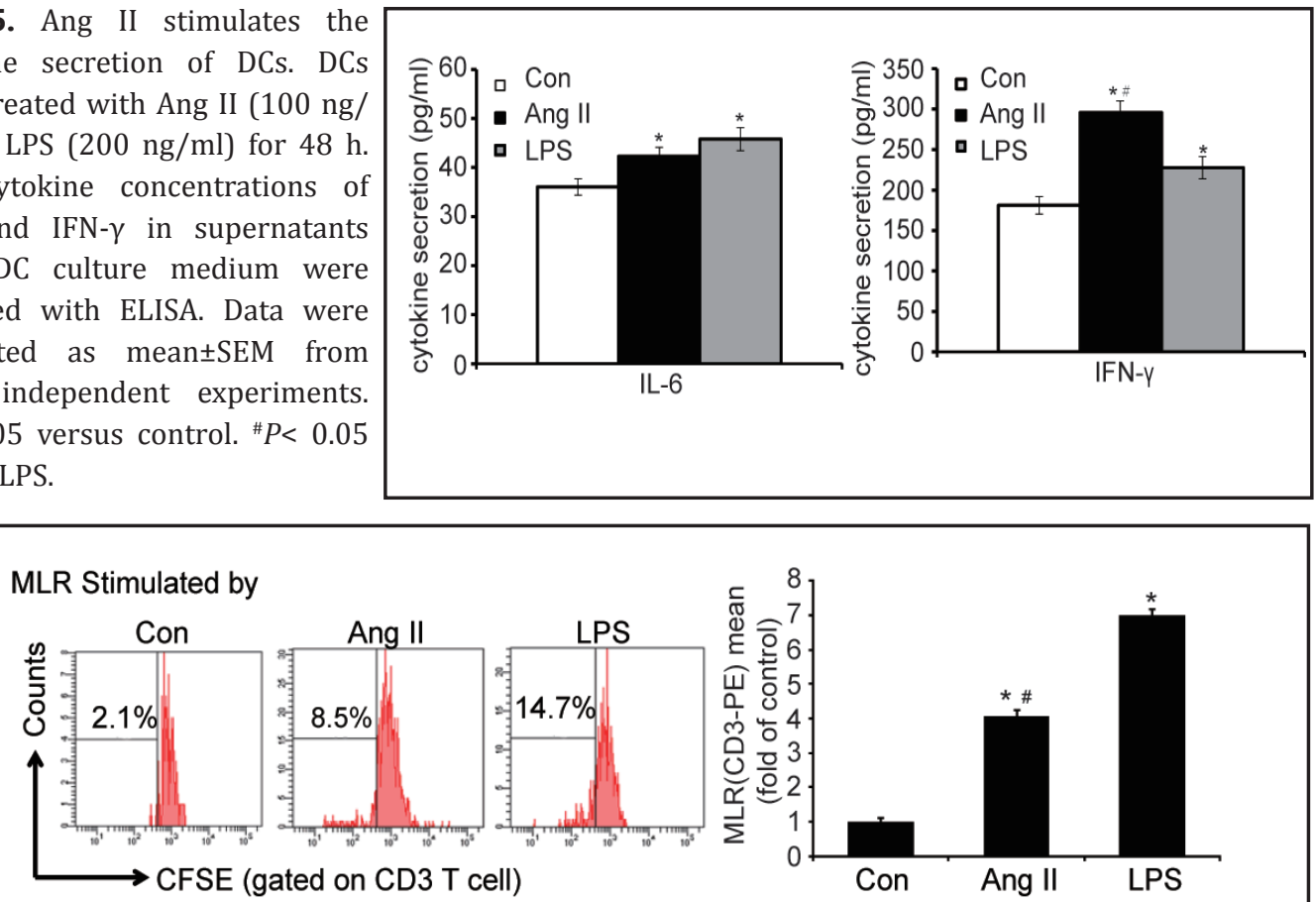

Fig. 6. Ang II promotes DC-mediated T cell proliferation. DCs were treated with Ang II (100 ng/ml) or LPS $(200 \mathrm{ng} / \mathrm{ml})$ for $48 \mathrm{~h}$ and then treated with Mitomycin C. Cells were then washed and $10^{5} \mathrm{DCs} /$ well were incubated with $10^{6}$ allogeneic lymphocytes in 12-well plates for 5 days. At day 5, cells were harvested, and the early markers CD69 and CD25 of T cells were with the fluorescent dye CFSE and analyzed by flow cytometry by gating on the CD3 lymphocyte population. The numbers indicates the percentages of positive cells. A representative experiment was shown for each condition. Data were presented as mean \pm SEM from three independent experiments. ${ }^{*} P<0.05$ versus control. ${ }^{*} P<0.05$ versus LPS.

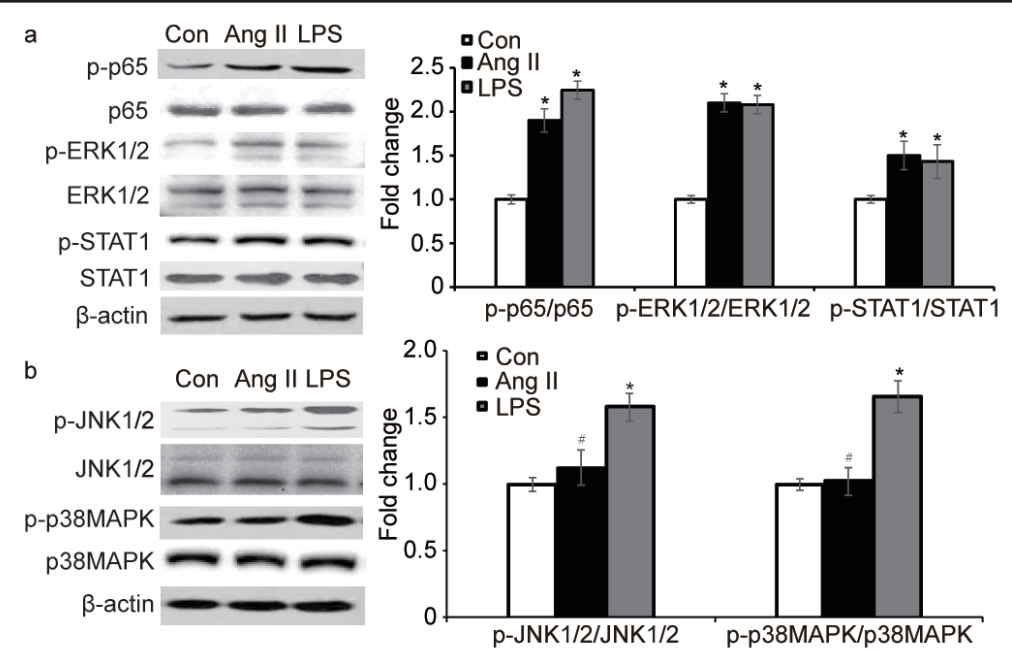

Fig. 7. The effect of Ang II on activation of NF- $\kappa B$, MAPKs and STAT1 in DCs. DCs were treated with Ang II $(100 \mathrm{ng} / \mathrm{ml})$ or LPS (200 ng/ml) for different time-points. Representative Western blots showed expression levels of total and phospho-p65/NF-kB, total and phospho-ERK1/2, and total and phospho-STAT3 (a), and total and phospho-JNK1/2, total and phospho-p38 MAPK (b). The intensity of protein bands was quantified and shown as the ratio of phosphorylated protein/total protein to control $(0 \mathrm{~min})$ after normalization by $\beta$-actin (right). Data were expressed as mean \pm SEM for three independent experiments. ${ }^{*} \mathrm{P}<0.05,{ }^{\#} P<0.05$ versus LPS. 


\section{Ang II activated DCs through multiple signaling pathways}

To elucidate the molecular mechanism for Ang II and LPS to regulate DCs, we examined activation of NF- $\kappa \mathrm{B}$, mitogen-activated protein kinase (MAPK) and signal transducers and activators of transcription (STAT1) signaling, which are known to play a critical role in DC antigen presentation and T-cell-dependent immune responses. As shown in Fig. 7, Ang II treatment significantly increased the levels of p65/NF-kB, ERK1/2 and STAT1 phosphorylation, but had no effect on the phosphorylation of JNK1/2 and p38 MAPK compared with control. LPS treatment markedly increased the levels of phosphorylated p65/ NF-kB, ERK1/2, STAT1, JNK1/2 and p38 MAPK (Fig. 7). These results suggested that Ang II and LPS induce the activation of DCs via different signal pathways with some overlapping.

\section{Discussion}

In the present study, we investigated the potential role of Ang II in promoting DC activation. We found that Ang II has similar impact to LPS in the regulation of DCs. Ang II treatment significantly suppressed the proliferation and phagocytic activity of DCs, but promoted the DC maturation, migration and the expression of pro-inflammatory cytokines by DCs. Ang II also promoted DC-mediated T cell proliferation. These effects were associated with activation of p65/NF- $\mathrm{BB}, \mathrm{ERK} 1 / 2$ and STAT1 signaling pathways in DCs.

The roles of renin-angiotensin-aldosterone system (RASS) in blood pressure regulation have been well documented. The current rationale for routine use of angiotensin receptor blocker (ARB) or angiotensin converting enzyme inhibitors (ACEI) is to lower the blood pressure in hypertensive patients. The pro-inflammatory actions of Ang II have received increasing attention. Elevated plasma level of Ang II has been documented in patients with hypertension, myocardial infarction and heart failure [10-12]. Ang II is able to induce the generation of reactive oxygen species and the activation MAPKs and NF- $\kappa B$ pathways in the heart, consequently resulting in cardiac hypertrophy, fibrosis and dysfunction [13].

DCs are key modulators of immunity, pivotal in directing innate and adaptive immune responses, and play a regulatory role for DCs in cardiovascular diseases (CVD)-associated immune responses. In general, most patient studies show decreased blood DC numbers in CAD patients. One possibility for the decrease in circulating DCs might be their enhanced recruitment to the disease sites, such as plaque or the ischemic heart [14]. However, high levels of DCs were found in patients with hypertension [15]. T cells have been described to contribute to hypertension, a process that likely involves the priming by DCs [16]. Vinh et al. reported that the number of activated DCs was increased in spleen and lymph nodes of hypertensive mice. Abatacept (CD28 blocker) administration significantly prevents Ang IIinduced hypertension in mice, supporting contribution of DCs to Ang II-induced hypertension [17]. Moreover, in human atherosclerotic plaques, mature DCs accumulate within the plaque shoulder where they produce T-cell chemotactic (CCL19 and CCL21) and proinflammatory cytokines (IL-12, IL-23, TNF- $\alpha$ ) [18-20]. Importantly, DCs have the unique ability to induce $\mathrm{T}$-cell responses by presenting antigens to naive T cells. For example, DCs, isolated from the aorta and the valves of wild-type mice, have the capacity to present antigens to $\mathrm{CD}^{+} \mathrm{T}$ cells, indicating that these cells are able to elicite a T-cell response [21]. Notably, DCs express Ang II receptors. Ang II treatment can induce human and murine DC maturation and activation in vivo and in vitro [22]. Consistent with these findings, our results demonstrated that Ang II has important functions in the regulation of the proliferation, maturation, migration, phagocytosis, and communication with T cells of DCs, and these effects were, at least in part, due to the activation of NF- $\mathrm{KB}, \mathrm{ERK} 1 / 2$ and STAT1 signalling pathways.

In conclusion, here we aimed to investigate the effect of Ang II on the regulation of DCs and the underlying mechanisms. We found that both Ang II and LPS are important regulators of DCs during the inflammatory responses. These findings may give a comprehensive insight the role of DCs in Ang II-induced cardiovascular disease and a potential therapeutic strategy for the suppression of immune diseases.

\section{KARGER}




\section{Cellular Physiology Cell Physiol Biochem 2017;42:1550-1558 \begin{tabular}{l|l} 
DOI: 10.1159/000479272, & $\begin{array}{l}\text { O 2017 The Author(s). Published by S. Karger AG, Basel } \\
\text { www.karger.com/cpb }\end{array}$ \\
\hline and Biochemistry
\end{tabular}}

Meng et al.: Ang II Activates DCs

\section{Acknowledgments}

This work was supported by the China National Natural Science Funds (No. 81100183 and 81670380), grants from 973 Program (2012CB517802) and Luhe Hospital Research foundation (No.lhq201502).

\section{Disclosure Statement}

The authors declared no conflict of interest.

\section{References}

1 Banchereau J, Steinman RM: Dendritic cells and the control of immunity. Nature 1998;392:245-252.

2 Banchereau J, Briere F, Caux C, Davoust J, Lebecque S, Liu YJ, Pulendran B, Palucka K: Immunobiology of dendritic cells. Annu Rev Immunol 2000;18:767-811.

3 Sathe P, Wu L: The network of cytokines, receptors and transcription factors governing the development of dendritic cell subsets. Protein Cell 2011;2:620-630.

-4 Joffre O, Nolte MA, Sporri R, Reis E, Sousa C: Inflammatory signals in dendritic cell activation and the induction of adaptive immunity. Immunol Rev 2009; 227:234-247.

-5 Lapteva N, Nieda M, Ando Y, Ide K, Hatta-Ohashi Y, Dymshits G, Ishikawa Y, Juji T, Tokunaga K: Expression of renin-angiotensin system genes in immature and mature dendritic cells identified using human cDNA microarray. Biochem Biophys Res Commun 2001;285:1059-1065.

-6 Lima TM, Sampaio SC, Petroni R, Brigatte P, Velasco IT, Soriano FG: Phagocytic activity of LPS tolerant macrophages. Mol Immunol 2014;60:8-13.

7 Guo F, Chen XL, Wang F, Liang X, Sun YX, Wang YJ: Role of angiotensin II type 1 receptor in angiotensin IIinduced cytokine production in macrophages. J Interferon Cytokine Res 2011;31:351-361.

8 Li M, Liu J, Han C, Wang B, Pang X, Mao J: Angiotensin II induces the expression of c-reactive protein via MAPK-dependent signal pathway in U937 macrophages. Cell Physiol Biochem 2011;27:63-70.

-9 Chen C, Meng Y, Wang L, Wang HX, Tian C, Pang GD, Li HH, Du J: Ubiquitin-activating enzyme E1 inhibitor

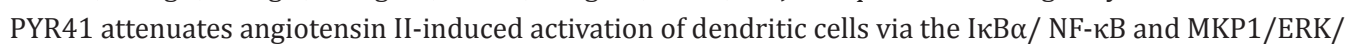
STAT1 pathways. Immunol 2014;142:307-319.

10 Liu PP, Maggioni A, Velazquez EJ: Use of valsartan in post-myocardial infarction and heart failure patients. J Renin Angiotensin Aldosterone Syst 2006;S:19-20.

11 Lemarié CA, Schiffrin EL: The angiotensin II type 2 receptor in cardiovascular disease. Clin Sci 2016;130:1307-1326.

-12 Benigni A, Cassis P, Remuzzi G: Angiotension II revisited: new roles in inflammation, immunology and aging. EMBO Mol Med 2010;2:247-257.

13 Marchesi C, Paradis P, Schiffrin EL: Role of the renin-angiotensin system in vascular inflammation. Trends Pharmacol Sci 2008;29:367-374.

14 Van Vré EA, Van Brussel I, Bosmans JM, Vrints CJ, Bult H: Dendritic cells in human atherosclerosis: from circulation to atherosclerotic plaques. Mediators Inflamm DOI:10.1155/2011/941396.

-15 Dieterlen MT, John K, Reichenspurner H, Mohr FW, Barten MJ.Dendritic cells and their role in cardiovascular diseases: a view on human studies. J Immunol Res DOI:10.1155/2016/5946807.

16 Guzik TJ, Hoch NE, Brown KA, McCann LA, Rahman A, Dikalov S, Goronzy J, Weyand C, Harrison DG: Role of the $\mathrm{T}$ cell in the genesis of angiotensin II induced hypertension and vascular dysfunction. J Exp Med 2007;204:2449-2460.

17 Vinh A, Chen W, Blinder Y, Weiss D, Taylor WR, Goronzy JJ, Weyand CM, Harrison DG, Guzik TJ: Inhibition and genetic ablation of the B7 / CD28 T-cell costimulation axis prevents experimental hypertension. Circulation 2010;122:2529-2537. 
18 Yilmaz A, Lochno M, Traeg F, Cicha I, Reiss C, Stumpf C, Raaz D, Anger T, Amann K, Probst T, Ludwig J, Daniel WG, Garlichs CD: Emergence of dendritic cells in rupture-prone regions of vulnerable carotid plaques. Atherosclerosis 2004;176:101-110.

19 Li L, Hu M, Zhang C, Li J, Rong R, Zhu T, Jia Y: Endothelin receptor down-regulation mechanisms protect against cellular hypoxia injury in rat vascular endothelial cells. Cell Physiol Biochem 2016;40:1443-1454.

20 Liang B, Wang X, Zhang N, Yang H, Bai R, Liu M, Bian Y, Xiao C, Yang Z: Angiotensin-(1-7) attenuates angiotensin II-induced ICAM-1,VCAM-1, and MCP-1 expression via the MAS receptor through suppression of P38 and NF-Kb pathway in HUVECs. Cell Physiol Biochem 2015;35:2472-2482.

21 Shortman K, Naik SH: Steady-state and inflammatory dendritic-cell development. Nat Rev Immunol 2007; 7:19-30.

22 Lateva N, Nieda M, Ando Y, Ide K, Hatta-Ohashi Y, Dymshits G, Ishikawa Y, Juji T, Tokunaga K: Expression of renin-angiotensin system genes in immature and mature dendritic cells identified using human cDNA microarray. Biochem Biophys Res Commun 2001;285:1059-1065. 